Tropical Journal of Pharmaceutical Research June 2015; 14 (6): 1013-1019

ISSN: $1596-5996$ (print); 1596-9827 (electronic)

(C) Pharmacotherapy Group, Faculty of Pharmacy, University of Benin, Benin City, 300001 Nigeria.

All rights reserved.

Available online at http://www.tjpr.org

Original Research Article

http://dx.doi.org/10.4314/tjpr.v14i6.11

\title{
Genotype and Haplotype Analysis of $A B C B 1$ at 1236, 2677 and 3435 among Jordanian Population
}

\author{
Ola Al-Diab ${ }^{1 *}$, Al-Motassem Yousef ${ }^{1}$, Enas Al Manassrah ${ }^{2}$, Ahmad Masadeh $^{3}$, \\ Muhammed Olemat ${ }^{3}$, Hisham Qosa ${ }^{4}$, Athar Kherbash ${ }^{1}$ and Nailya R Bulatova ${ }^{1}$ \\ ${ }^{1}$ Department of Biopharmaceutics and Clinical Pharmacy, Faculty of Pharmacy, The University of Jordan, Amman, ${ }^{2}$ Clinical \\ Pharmacy Department, Al-Basheer Hospital, Amman, ${ }^{3}$ Clinical Pharmacy Department, Royal Medical Services, Amman, \\ Jordan, ${ }^{4}$ Department of Basic Pharmaceutical Science, College of Pharmacy, University of Louisiana at Monroe, Monroe, LA, \\ USA
}

*For correspondence: Email: o.diab@ju.edu.jo; olaaldiab@gmail.com; ayousef@ju.edu.jo; Tel: 962-777486930; Fax: 962-65339649

\begin{abstract}
Purpose: To determine the frequencies of important allelic variants and their haplotype frequencies of the gene among Jordanian population and to compare findings with those reported for other ethnic groups.

Methods: Genotyping of ABCB1 (C1236T, G2677T/A and C3435T) was carried out on unrelated healthy Jordanian subjects. Different allelic variants were determined using polymerase chain reactionrestriction fragment length polymorphism (PCR-RFLP). The haplotype frequencies of these three SNPS were analyzed and compared them with those of other reported populations. Haplotype frequencies were calculated using Golden Helix Tree software and Linkage disequilibrium was represented by D".

Results: $A B C B 1 C 3435 T$ allele frequencies for $C$ allele and $T$ allele were 0.57 and 0.43 , respectively. For ABCB1 G2677T/A the allele frequencies for $G$ allele, $T$ allele, and $A$ allele were $0.65,0.32$ and 0.0 , respectively. As for $A B C B$ C1236T, its allele frequencies were 0.65 for $C$ allele and 0.35 for $T$ allele. C1236T, G2677T/A, and C3435T SNPs were expected to be structured in 8 different haplotypes with GC-C (37.6.0 \%), T-T-T (18.6\%), G-C-T (14.3\%) and T-T-C (12\%) that were most prominent. The haplotype frequency distribution of our study group was found to be significantly different from those of Chinese, Indian, Japanese, African and Caucasian $(p<0.0001)$ and resemble Ashkenazi Jewish and Slovenian populations $(p>0.05)$.

Conclusion: In addition to earlier studies, the findings of the current study provide evidence that suggest the use of genetic polymorphisms of ABCB1 SNPS as markers for ethnicity and ancestral origin. The analysis of haplotype and genotype can be useful in identifying the relation between ABCB1 polymorphism, disease susceptibility and drug disposition.
\end{abstract}

Keywords: Genotype, Allele, MDR1, ABCB1, Polymorphism, Haplotype frequencies

Tropical Journal of Pharmaceutical Research is indexed by Science Citation Index (SciSearch), Scopus, International Pharmaceutical Abstract, Chemical Abstracts, Embase, Index Copernicus, EBSCO, African Index Medicus, JournalSeek, Journal Citation Reports/Science Edition, Directory of Open Access Journals (DOAJ), African Journal Online, Bioline International, Open-J-Gate and Pharmacy Abstracts

\section{INTRODUCTION}

P-glycoprotein (P-gp), and the product of the multidrug resistance (MDR1) gene (recently renamed $A B C B 1$ ) plays an important role in the bioavailability of a wide variety of drugs and are involved in drug-drug interaction in humans [1]. $A B C B 1$ is highly polymorphic and a number of mutations have been documented in various ethnic populations [2]. Recently, genetic variations of $A B C B 1$ gene have been studied very extensively, and over 50 single nucleotide 
polymorphisms (SNPs) have been reported $[1,3]$. The allelic frequency of $A B C B 1$ SNPs varies widely among different ethnic groups [2,4]. Among many variants, C3435T (rs1045642) in exon 26 (lle1145lle); G2677T/A (rs2032582) in exon 21 (Ala893Ser/Thr) and C1236T (rs1128503) in exon 12 (Gly412Gly) are more frequent than other SNPs [5] and have been shown to affect the expression and function of $P$ gp [6-8]. These three SNPs have been the focus of many pharmacokinetic and disease association studies with controversial results [9]. The variant alleles of the three most common coding SNPs, at nucleotides 1236, 2677 and 3435 are in high Linkage disequilibrium as has been commonly found in multiple studies $[4,9]$, and most haplotype analyse were carried out using these three SNPs. Kim et al named the haplotype 1236C, 2677G, 3435C as ABCB1*1, and the mutant alleles haplotype 1236T, 2677T, $3435 \mathrm{~T}$, was named as $A B C B 1^{*} 2$ [8].

Haplotype analysis, in addition to the customary analysis of SNPs, may play an important role in the identification of genetic variations between ethnic groups. In addition, the functional effects of P-gp activity may also be related to haplotypes in the $A B C B 1$ gene. The frequencies of the important allelic variants in $A B C B 1$ genes have been extensively studied in many ethnic groups. In the present study, we report the allele frequencies of $A B C B 1 \mathrm{C} 1236 \mathrm{~T}, \mathrm{G} 2677 \mathrm{~T} / \mathrm{A}$ and C3435T SNPs and their haplotype in a sufficiently large sample of apparently healthy unrelated Jordanian population. To our knowledge, it is the first haplotype frequency study of the Jordanian population reported to date.

While native Jordanians are mostly descended from people of villagers and Bedouin descent originating in the Arabian Peninsula [10], ethnically, the Jordanians represent a mixed stock. Most of the population is Arab (approximately $98 \%$ ) while $1 \%$ of the population is Armenian, and another $1 \%$ is Circassian. There are also small Kurd, Druze, and Chechen minorities [11].

\section{EXPERIMENTAL}

\section{Subjects}

Three hundred and thirty nine (339) apparently healthy unrelated Jordanian subjects were included in this study after detailed explanation of the purpose of the study followed by obtaining written informed consent for genetic analysis from all of them. The participants had an average age of $46.1 \pm 15$ years and majority of them were men $(n=235,69 \%)$. The study was approved by local Research Ethics Committees of the Jordan University Hospital (approval reference number $M / C / A / 111 / 1519$, $T H / F / 3 / 1 / 1945$ and $\mathrm{TH} / \mathrm{F} / 3 / 1 / 2046$ ), the WMA declaration of Helsinki was followed [12].

From each subject, $1 \mathrm{ml}$ of blood was collected. Genomic DNA was isolated from the blood using Wizard Genomic ${ }^{\circledR}$ (DNA purification kit) (Promega Corporation, USA). The isolated DNA samples were prepared for genotyping.

\section{Genotype and haplotype analysis}

Polymerase chain reaction (PCR) and restriction fragment length polymorphism (RFLP) were used to identify different SNPs of ABCB1 (C1236T, G2677T/A and C3435T). Primers utilized, PCR annealing conditions and restriction enzymes are summarized in Table 1.

The findings of PCR-RFLP were validated as follows:

Table 1: Primer sequences in different SNPs and restriction enzymes used

\begin{tabular}{|c|c|c|c|}
\hline ABCB1 SNPs & Primers used & $\begin{array}{l}\text { Annealing } \\
\text { temperature }\left({ }^{\circ} \mathrm{C}\right)\end{array}$ & $\begin{array}{c}\text { Restriction } \\
\text { enzyme* }\end{array}$ \\
\hline C1236T & $\begin{array}{l}\text { Forward: ctcgaaaagaagttaaggtaca } \\
\text { Reverse: atctcaccatcccctctgtg }\end{array}$ & 58 & HaellI \\
\hline G2677T/A & $\begin{array}{l}\text { Forward: tttagtttgactcaccttcccg } \\
\text { Reverse: ggcacctatagcctgcaaaaca }\end{array}$ & 60 & Banl, Rsal \\
\hline C3435T & $\begin{array}{l}\text { Forward: gtaacttggcagttcagtg } \\
\text { Reverse: ataaacagcctgggagcatg }\end{array}$ & 56 & Dpnll \\
\hline
\end{tabular}

${ }^{*}$ PCR products were digested with a restriction enzyme that could distinguish between genotypes and was chosen using the website http://tools.neb.com/NEBcutter2/index.php 
(1) PCR is sensitive to reagents contaminated with foreign DNA. A negative control contained all PCR components except the DNA template was run simultaneously to rule out contaminated reagents;

(2) Around $15 \%$ of all samples were repeated to confirm findings of the PCR-RFLP;

(3) The PCR-RFLP results of $10 \%$ of samples were confirmed for by direct DNA sequencing using BigDye Terminator Cycle Sequencing on 3730xI DNA sequencer (Macrogene ${ }^{\circledR}$ Co., Korea).

\section{Statistical analysis}

Allele and genotype frequencies for different alleles were estimated from the results of the above PCR-RFLP test. This estimation was carried out as earlier reported [13]. Genotype and allele frequency were matched to expectation by Hardy-Weinberg Equilibrium; differences in allele frequencies between Jordanians and other ethnic populations were assessed using Chi square test. Haplotype was analyzed using Helix Tree Genetics Analysis Software, Golden Helix Inc. $P<0.05$ was considered statistically significant for population comparisons.

Linkage disequilibrium was calculated using equation [14] and quantified by ' $D$ ' and rHo square $\left(R^{2}\right)$ values, also Linkage disequilibrium were calculated using MIDAS software [15].

\section{RESULTS}

\section{$A B C B 1$ SNPs frequencies}

The frequencies of $A B C B 1$ C1236T, G2677T/A and C3435T genotype for the 339 subjects are summarized in Table 2. Using Hardy-Weinberg equilibrium $(\mathrm{H}-\mathrm{W})$ there was no significant difference between the findings of the current study and H-W expectation ( $p>0.05$, ChiSquare) (Table 2). Not all samples were successfully analyzed for the three SNPs because either we ran out of sample $(n=6)$, failure of DNA extraction $(n=1)$, or failure of $\operatorname{PCR}(n=4)$.

\section{$A B C B 1$ haplotype}

The most frequent haplotypes are listed in Table 3. Linkage disequilibrium was described by D'; the standardized, pair wise Linkagedisequilibrium value D' was calculated for each pair of markers. In the current study, loci 2677 and 3435 show relatively strong Linkage disequilibrium (Lewontin's coefficient [D'] = $\left.0.765 ; r^{2}=0.426\right)$, However, 1236-2677 and 1236-3435 show weak Linkage disequilibrium $\left(\left[D^{\prime}\right]=0.303 ; r^{2}=0.087\right.$ and $\left[D^{\prime}\right]=0.319 ; r^{2}=$ 0.091 respectively). Table 4 shows T-allele frequencies among different ethnicities while the haplotype frequencies among different ethnicities are listed in Table 5.

Table 2: The observed and expected genotype distribution of the tested variants among the Jordanian subjects according to Hardy-Weinberg equilibrium

\begin{tabular}{|c|c|c|c|c|c|}
\hline \multicolumn{2}{|c|}{ Tested SNP } & $\mathbf{N}$ & $\begin{array}{c}\text { Observed frequency } \\
(\%)\end{array}$ & $\begin{array}{c}\text { Predicted frequency } \\
(\mathrm{H}-\mathrm{W})(\%)\end{array}$ & $p$-value \\
\hline \multirow[t]{4}{*}{$\overline{A B C B 1}$} & 3435 & 337 & & & \\
\hline & CC & 112 & 33.2 & 32.6 & \\
\hline & CT & 160 & 47.5 & 49.1 & 0.56 \\
\hline & TT & 65 & 19.3 & 18.3 & \\
\hline \multirow[t]{6}{*}{$A B C B 1$} & 2677 & 329 & & & \\
\hline & GG & 130 & 39.25 & 42 & \\
\hline & GT & 164 & 50.75 & 45.6 & 0.11 \\
\hline & GA & 0 & 0 & 0 & \\
\hline & TT & 35 & 10 & 12.4 & \\
\hline & AA & 0 & 0 & 0 & \\
\hline \multirow[t]{4}{*}{ ABCB1 } & 1236 & 338 & & & \\
\hline & CC & 142 & 29.8 & 35.2 & \\
\hline & CT & 154 & 59.2 & 48.2 & 1.00 \\
\hline & TT & 42 & 11 & 16.6 & \\
\hline
\end{tabular}

Total number of subjects was 339. Numbers of genotypes do not add up to 339 because: ran out of sample, failure in DNA extraction, and/or failure of PCR 
Table 3: Haplotype frequencies among Jordanians

\begin{tabular}{llll}
\hline Haplotype * & EM Probability & CHM Prob \\
\hline CGC & 0.376 & 0.276 \\
TTT & 0.186 & 0.11 \\
CGT & 0.143 & 0.16 \\
TTC & 0.12 & 0.11 \\
TGT & 0.06 & 0.10 \\
TGC & 0.06 & 0.11 \\
CTT & 0.03 & 0.06 & \\
CTC & 0.018 & 0.08 & \\
\hline Haplotypes order: & C3435T-G2677T/A-C1236T; CHM: Composite Haplotype Method; M: Expectation &
\end{tabular}

Table 4: Comparison of the T-allele frequencies of ABCB1 reported from different ethnic populations

\begin{tabular}{|c|c|c|c|c|c|}
\hline Population & $\mathbf{N}$ & $3435(T)$ & 2677 (T/A) & $1236(\mathrm{~T})$ & References \\
\hline Jordanian & 339 & 0.43 & $0.32 / \mathrm{NA}$ & 0.35 & Current study \\
\hline Caucasians (USA) & 99 & 0.566 & $0.434 / 0.036$ & 0.459 & [16] \\
\hline $\begin{array}{l}\text { German } \\
\text { Polish } \\
\text { Slovenian }\end{array}$ & $\begin{array}{l}188 \\
139 \\
355\end{array}$ & $\begin{array}{c}0.52 \\
0.522 \\
0.47\end{array}$ & $\begin{array}{c}\text { Not reported } \\
0.414 / 0.576 \\
0.40 / \mathrm{NA}\end{array}$ & $\begin{array}{c}0.38 \\
0.414 \\
0.38\end{array}$ & $\begin{array}{l}{[5]} \\
{[17]} \\
{[18]}\end{array}$ \\
\hline $\begin{array}{l}\text { Asians } \\
\text { Japanese } \\
\text { Chinese } \\
\text { Indian }\end{array}$ & $\begin{array}{c}154 \\
207 \\
87\end{array}$ & $\begin{array}{l}0.406 \\
0.347 \\
0.632\end{array}$ & $\begin{array}{l}0.406 / 0.166 \\
0.364 / 0.114 \\
0.598 / 0.069\end{array}$ & $\begin{array}{l}0.656 \\
0.638 \\
0.672\end{array}$ & $\begin{array}{l}{[16]} \\
{[19]} \\
{[20]}\end{array}$ \\
\hline Saudi Arabia & 189 & 0.422 & $0.40 / 0.008$ & 0.437 & [21] \\
\hline Morocco & 100 & 0.355 & $0.275 / \mathrm{NA}$ & 0.325 & [22] \\
\hline African-Americans & 99 & 0.202 & $0.1 / 0.005$ & $\begin{array}{c}\text { Not } \\
\text { reported }\end{array}$ & [23] \\
\hline $\begin{array}{l}\text { Brazilian ( white) } \\
\text { Brazilian ( black) }\end{array}$ & $\begin{array}{l}106 \\
100\end{array}$ & $\begin{array}{l}0.45 \\
0.31\end{array}$ & $\begin{array}{l}0.38 / 0.01 \\
0.18 / 0.01\end{array}$ & $\begin{array}{l}0.41 \\
0.33\end{array}$ & $\begin{array}{l}{[24]} \\
{[24]}\end{array}$ \\
\hline Ashkenazi Jewish & 101 & 0.50 & $0.41 / \mathrm{NA}$ & 0.42 & [25] \\
\hline
\end{tabular}

Table 5: Comparison of haplotype frequencies of ABCB1 reported for different ethnic populations

\begin{tabular}{|c|c|c|c|c|c|c|}
\hline Population & Sample & $\begin{array}{c}\text { CGC } \\
(\%)\end{array}$ & $\begin{array}{l}\text { TTT } \\
(\%)\end{array}$ & $\begin{array}{c}\text { Others } \\
(\%)\end{array}$ & $P$ - value* & References \\
\hline $\begin{array}{l}\text { Jordanian } \\
\text { Caucasian }\end{array}$ & 339 & 37.6 & 18.6 & 43.4 & & Current study \\
\hline Slovenian & 355 & 40.1 & 23.1 & 36.8 & 0.156 & [18] \\
\hline French & 222 & 44 & 35.3 & 20.7 & $<0.001$ & [26] \\
\hline Turkish & 107 & 25 & 33.7 & 41.3 & 0.03 & [27] \\
\hline Saudi Arabian & 189 & 48.8 & 35.5 & 15.7 & $<0.00001$ & [21] \\
\hline Moroccan & 100 & 53 & 21 & 26 & 0.034 & [22] \\
\hline African American & 99 & 43.6 & 8.7 & 47.7 & 0.036 & [23] \\
\hline $\begin{array}{l}\text { Brazilians (black) } \\
\text { Asian }\end{array}$ & 100 & 58.9 & 15.8 & 25.3 & $<0.001$ & [24] \\
\hline Chinese & 207 & 16.8 & 35.7 & 47.5 & $<0.0001$ & [19] \\
\hline Indian & 68 & 17.56 & 31.38 & 51.06 & $<0.0001$ & [28] \\
\hline Korean & 232 & 18.6 & 32.2 & 49.2 & $<0.0001$ & {$[29]$} \\
\hline Ashkenazi Jewish & 101 & 31.7 & 23.6 & 44.7 & 0.57 & [25] \\
\hline
\end{tabular}

$P$-values were calculated using: http://www.danielsoper.com/statcalc3/calc.aspx?id=58 


\section{DISCUSSION}

Several lines of evidence suggest a role for the multidrug resistance gene $A B C B 1 / M D R 1)$ to disease susceptibility, such as Crohns' disease and cancer [30]. MDR1 is highly expressed in drug-resistant cancer cells. Several chemotherapeutic agents are affected by MDR1 genetic polymorphism mainly platinum-based chemotherapy response in lung cancer [30]. The need to study these different polymorphisms and haplotypes has been necessary to evaluate the inter-individual variation in disease progression, response and treatment especially chemotherapeutic agents.

$A B C B 1$ is a highly polymorphic gene, and three SNPs that were extensively studied in healthy populations as well as in different clinical conditions $[2,7,30]$ were investigated in this research. The frequencies of $A B C B 1$ allelic variants differ widely among different ethnic groups $[4,8]$.

The frequency of the ABCB1 C1236T, G2677T/A and C3435T mutant alleles among the Jordanian population was $35 \%, 32 \%$ and $43 \%$ respectively, which is in the range comparable with other Caucasians; Americans, German and Turkish populations. On the other hand, the frequencies among Jordanians are quite different from those reported for Japanese, Chinese African American, and Moroccan. Table 4 is a comparison between the Jordanian population SNPs frequencies from the current study and other ethnic populations.

Since the frequency of the polymorphism at 3435 varies according to ethnicity, it is no surprise that the haplotype which carries this SNP shows a similar pattern. It is clear that people of African origin carry predominantly the wild-type (CGC) allele and not the haplotype allele (TTT) $[6,23]$. In Caucasian people, the frequency of CGC and TTT alleles is approximately the same $[6,23,26]$. It is interesting that the TTT haplotype is the predominant genotype among Asian and Indian populations. Table 5 summarizes the haplotype distribution of $A B C B 1$ among healthy individuals in different races.

Regarding haplotype frequencies among Jordanian population, 8 different haplotypes appeared in our analysis, the most frequent haplotypes were CGC (37.6\%), TTT (18.6\%), CGT (14.3\%), TTC (12\%) the other haplotypes had frequencies less than $6 \%$ (Table 3). These four most frequent haplotypes among Jordanian population were also reported to be the four most frequent haplotypes among Turkish, Saudi
Arabia and Jewish populations [21,25,27]. The Wild type CGC is the predominant haplotype among Jordanian as is the case among other Caucasian population [4], but not among Asian, Japanese and African populations [19,23,28], in which TTT is the predominant haplotype.

When considering the two haplotypes CGC and TTT, the reported literature reveals that Slovenian and Jewish Populations were the closest to the Jordanians [25,27]. These three populations had CGC as the most frequent haplotype followed by TTT, then by CGT (Table 5). A new study that has been published among Saudi Arabian population regarding haplotype frequencies [21], revealed that CGC and TTT are the predominant haplotypes with higher frequencies compared to Caucasian and Jordanian in the present study (Table 5). However, the most frequent haplotypes in Saudi Arabian and Moroccan populations are similar to our study but significantly with different frequencies [21,22].

Linkage disequilibrium has been reported between the most common polymorphisms found in $A B C B 1$ at positions C1236T, G2677T/A, and C3435T $[4,8,27]$. Of the synonymous SNPs, two (C1236T and C3435T) were linked to a nonsynonymous SNP (G2677T/A, Ala893Ser) and occurred in $62 \%$ of the European Americans, but in only $13 \%$ of the African Americans tested [8]. Additionally, previous research reported statistically significant Linkage disequilibrium between all C1236T, G2677T/A, and C3435T SNPs $[4,27]$; However, our results indicated that only loci 2677 and 3435 showed relatively strong Linkage disequilibrium (Lewontin's coefficient [D'] $\left.=0.76 ; r^{2}=0.42\right)$, as was also observed $[18,27]$.

\section{Limitation of the study}

There are more than 50 known SNPs for MDR1 gene and most studies only analyzed these three SNPs as they are considered the most frequent SNPs in most populations and are known to influence the activity of P-glycoprotein. Only 3 SNPs were analyzed for haplotyping in this study which may limit the interpretation of the results. Furthermore, the SNPs were genotyped by PCRRFLP and only $10 \%$ of the samples were sequenced to confirm the result when a better result may have been obtained if all samples were confirmed by sequencing.

\section{CONCLUSION}

The current study has successfully determined common allelic variants in $A B C B 1$ among Jordanian population, some of which are being 
reported for the first time among the population. The frequencies obtained are comparable to data previously reported in other populations of Caucasian origin but differ from that observed in African and Asian populations. Furthermore, haplotype frequencies are different from those among African, Asian and other populations, but resemble those among Jewish and Slovenian population. The findings of the current study, in addition to earlier studies, provide evidence to suggest the use of genetic polymorphisms of $A B C B 1$ SNPs as markers for ethnicity and ancestral origin.

\section{ACKNOWLEDGEMENT}

The authors would like to thank all individuals who agreed to participate as subjects of the study. This study was supported, in part, by unconditional grant from the Deanship of Scientific Research (The University of Jordan, Jordan).

\section{REFERENCES}

1. Yan-Hong L Y-HW, Yan L, Ling Y. MDRI Gene Polymorphisrns and Clinical Relevance. Acta Genetica Sinica 2005; 33: 93-104.

2. Zhou SF. Structure, function and regulation of $P$ glycoprotein and its clinical relevance in drug disposition. Xenobiotica 2008; 38(7-8): 802-832.

3. Ishikawa $T$, Onishi $Y$, Hirano $H$, Oosumi K, Nagakura $M$, Tarui S. Pharmacogenomics of drug transporters: a new approach to functional analysis of the genetic polymorphisms of ABCB1 (P-glycoprotein/MDR1). Biol Pharm Bull 2004; 27(7): 939-948.

4. Fung KL, Gottesman MM. A synonymous polymorphism in a common MDR1 (ABCB1) haplotype shapes protein function. Biochim Biophys Acta 2009; 1794(5): 860-871.

5. Hoffmeyer $S$, Burk $O$, von Richter $O$, Arnold HP, Brockmoller J, Johne A, Cascorbi I, Gerloff T, Roots I, Eichelbaum $M$ et al. Functional polymorphisms of the human multidrug-resistance gene: multiple sequence variations and correlation of one allele with $P$ glycoprotein expression and activity in vivo. Proc Natl Acad Sci USA 2000; 97 (7): 3473-3478.

6. Fromm MF. The influence of MDR1 polymorphisms on $P$ glycoprotein expression and function in humans. Adv Drug Deliv Rev 2002; 54 (10): 1295-1310.

7. Marzolini C, Paus E, Buclin T, Kim RB. Polymorphisms in human MDR1 (P-glycoprotein): recent advances and clinical relevance. Clin Pharmacol Ther 2004; 75(1): 13-33.

8. Kim RB, Leake BF, Choo EF, Dresser GK, Kubba SV, Schwarz UI, Taylor A, Xie HG, McKinsey J, Zhou S et al. Identification of functionally variant MDR1 alleles among European Americans and African Americans. Clin Pharmacol Ther 2001; 70(2): 189-199.

9. McDonagh EM, Whirl-Carrillo $M$, Garten $Y$, Altman RB , Klein TE, Biomarkers in Medicine in 6. 2011, "From pharmacogenomic knowledge acquisition to clinical applications: the PharmGKB as a clinical pharmacogenomic biomarker resource." $<$ <ttp://www. pharmgkb.org/redirect.jsp?p=http\%3A\%2 F\%2Fwww.ncbi.nlm.nih.gov\%2Fpubmed\%2F221036 13> pp 795-806.

10. Lowi MR. Water and power: the politics of a scarce resource in the Jordan River basin. Cambridge University Press, Cambridge; 1995.

11. The Royal Hashemite Court Keys to the Kingdom-The People of Jordan. http://www.kinghussein.gov.jo/ people.html. Accessed 18 Apr 2013

12. World Medical Association Declaration of Helsinki: ethical principles for medical research involving human subjects. JAMA 2000; 310(20): 2191-2194.

13. Brooker R. Genetics, Analysis and Principles, USA: McGraw-Hill; 2005.

14. Lewontin RC, Dunn LC. The Evolutionary Dynamics of a Polymorphism in the House Mouse. Genetics 1960; 45(6): 705-722.

15. Gaunt TR, Rodriguez S, Zapata C, Day IN. MIDAS: software for analysis and visualisation of interallelic disequilibrium between multiallelic markers. BMC Bioinformatics 2006; 7: 227

16. Komoto C, Nakamura T, Sakaeda T, Kroetz DL, Yamada T, Omatsu H, Koyama T, Okamura N, Miki I, Tamura $T$, et al. MDR1 haplotype frequencies in Japanese and Caucasian, and in Japanese patients with colorectal cancer and esophageal cancer. Drug Metab Pharmacokinet 2006; 21(2): 126-132.

17. Tan EK, Drozdzik M, Bialecka M, Honczarenko K, Klodowska-Duda G, Teo YY, Tang K, Wong LP, Chong SS, Tan $C$ et al. Analysis of MDR1 haplotypes in Parkinson's disease in a white population. Neurosci Lett 2004; 372(3): 240-244.

18. Potocnik U, Ferkolj I, Glavac D, Dean M. Polymorphisms in multidrug resistance 1 (MDR1) gene are associated with refractory Crohn disease and ulcerative colitis. Genes Immun 2004; 5 (7): 530-539.

19. Xu P, Jiang ZP, Zhang BK, Tu JY, Li HD. Impact of MDR1 haplotypes derived from C1236T, G2677T/A and C3435T on the pharmacokinetics of single-dose oral digoxin in healthy Chinese volunteers. Pharmacology 2008; 82(3): 221-227.

20. Chowbay B, Cumaraswamy S, Cheung YB, Zhou Q, Lee EJ. Genetic polymorphisms in MDR1 and CYP3A4 genes in Asians and the influence of MDR1 haplotypes on cyclosporin disposition in heart transplant recipients. Pharmacogenetics 2003; 13(2): 89-95.

21. Al-Mohizea AM, Alkharfy KM, Bagulb KM, Alghamdi AM, Al-Jenoobi Fl, Al-Muhsen S, Halwani R, Khalid Parvez M, Al-Dosari MS. Genetic variability and 
haplotype profile of MDR1 in Saudi Arabian males. Mol Biol Rep 2012; 39(12): 10293-10301.

22. Kassogue Y, Dehbi H, Nassereddine S, Quachouh M, Nadifi S. Genotype variability and haplotype frequency of MDR1 (ABCB1) gene polymorphism in Morocco. DNA Cell Biol 2013; 32(10): 582-588.

23. Kroetz DL, Pauli-Magnus $C$, Hodges $L M$, Huang CC, Kawamoto M, Johns SJ, Stryke D, Ferrin TE, DeYoung J, Taylor $T$ et al. Sequence diversity and haplotype structure in the human ABCB1 (MDR1, multidrug resistance transporter) gene. Pharmacogenetics 2003; 13(8): 481-494.

24. Estrela RC, Ribeiro FS, Carvalho RS, Gregorio SP, DiasNeto E, Struchiner CJ, Suarez-Kurtz G. Distribution of $A B C B 1$ polymorphisms among Brazilians: impact of population admixture. Pharmacogenomics 2008; 9(3): 267-276.

25. Kimchi-Sarfaty $C$, Marple $A H$, Shinar S, Kimchi AM, Scavo D, Roma MI, Kim IW, Jones A, Arora M, Gribar $J$ et al. Ethnicity-related polymorphisms and haplotypes in the human ABCB1 gene. Pharmacogenomics 2007; 8(1): 29-39.
26. Jeannesson E, Albertini L, Siest G, Gomes AM, Ribeiro $V$, Aslanidis $C$, Schmitz $G$, Visvikis-Siest $S$. Determination of ABCB1 polymorphisms and haplotypes frequencies in a French population. Fundam Clin Pharmacol 2007; 21(4): 411-8.

27. Gumus-Akay G, Rustemoglu A, Karadag A, Sunguroglu A. Haplotype-based analysis of MDR1/ABCB1 gene polymorphisms in a Turkish population. DNA Cell Biol 2010; 29(2): 83-90.

28. Tang K, Ngoi SM, Gwee PC, Chua JM, Lee EJ, Chong SS, Lee CG. Distinct haplotype profiles and strong linkage disequilibrium at the MDR1 multidrug transporter gene locus in three ethnic Asian populations. Pharmacogenetics 2002; 12(6): 437450.

29. Yi SY, Hong KS, Lim HS, Chung JY, Oh DS, Kim JR, Jung HR, Cho JY, Yu KS, Jang IJ, et al. A variant 2677A allele of the MDR1 gene affects fexofenadine disposition. Clin Pharmacol Ther 2004; 76(5): 418427.

30. Brambila-Tapia AJ. MDR1 (ABCB1) polymorphisms: functional effects and clinical implications. Rev Invest Clin 2013; 65(5): 445-454. 